\title{
Caracterização Físico-Química do Resíduo (Lodo) de ETA, no período de seca, em Várzea Grande - MT
}

\section{Waste's (Sludge's) WTS Physicochemical Characterization, in the dry season, in Várzea Grande - Mato Grosso}

\author{
1Thiago Magalhães Moraes de Souza, ${ }^{2}$ Aldecy de Almeida Filho \\ ${ }^{1}$ Engenheiro Civil - Faculdade de Arquitetura, Engenharia e Tecnologia (FAET), Universidade Federal de Mato \\ Grosso (UFMT) (thiagomega3@ gmail.com) \\ ${ }^{2}$ Professor Doutor do Departamento de Engenharia Sanitária e Ambiental (DESA) - FAET/UFMT \\ (aldecy_allmeida@yahoo.com.br))
}

\begin{abstract}
RESUMO: Este trabalho busca analisar a água bruta e o lodo produzido na Estação de Tratamento de Água (ETA), situada na cidade de Várzea Grande, Mato Grosso, visando a correta destinação deste material, seja no meio ambiente, seja por meio de alternativas como o seu reaproveitamento na própria estação, visando reduzir o desperdício de água, sobretudo na época de secas da região, período em que o estudo ocorreu. Estudou-se os parâmetros físico-químicos (potencial hidrogeniônico $(\mathrm{pH})$, cor, turbidez, demanda química de oxigênio (DQO), teor de sólidos sedimentáveis, totais, fixos e voláteis). Verificou-se que o resíduo da estação lançado em corpos hídricos não está de acordo os parâmetros definidos pela Resolução n. ${ }^{\circ}$ 430/2011 do Conselho Nacional do Meio Ambiente (CONAMA) (os teores de sólidos sedimentáveis estão acima do permitido). No entanto, há a possibilidade de dar uma destinação adequada a esse material por meio do reaproveitamento da água de lavagem dos filtros (teor de sólidos de $0,1 \%$ ) pela própria estação.
\end{abstract}

Palavras-chave: Resíduos sólidos; Destinação adequada do lodo; Recursos hídricos.

\begin{abstract}
This work aims to analyze the raw water and the sludge produced in the Várzea Grande city's Water Treatment Station (WTS), Mato Grosso, aiming the correct this material's disposal, either in the environment, either through alternatives like the material reuse at the WTS to reduce the waste water, especially during the dry season in the city, season that the study ocurred. The research studied the physicochemical parameters ( $\mathrm{pH}$, color, turbidity, biochemical oxygen demand (BOD), settleable total, fixed and volatile solids content). It was found that the station's residue released in watercourse is not according the parameters set by CONAMA 430/2011 (the settleable solid content is higher than it is allowed). However, it is possible to give an appropriate allocation to this material through of the reuse of backwash water filter $(0.1 \%$ solid contents $)$ by the station itself.

Keywords: Solid waste; Correct sludge's disposal; Water resources
\end{abstract}

\section{INTRODUÇÃO}

O número de pessoas que habitam o planeta cresce consideravelmente. No Brasil não é diferente, e por isso aumenta-se também os cuidados em relação à saúde da população. Em virtude disso, um dos pontos importantes é a necessidade de as residências usufruírem de um sistema de abastecimento que disponibilize água com qualidade e quantidade aceitável a elas, atendendo suas necessidades de higiene pessoal e alimentação (DANTAS JÚNIOR, 2012).

Com a consequente elevação populacional, aumenta-se com ela a quantidade de água que deve chegar aos lares e indústrias e em condições de serem utilizadas. No entanto, conforme o crescimento do poder financeiro das famílias, a quantidade de lixo por elas produzida também sofre a mesma mudança, pois o consumo dessas pessoas se eleva, descartando mais resíduos de forma inapropriada na natureza, contaminando o solo e os cursos de água. Por exemplo, Mercedes (1997) mostrou, através de seus estudos na cidade de Belo Horizonte, que quanto mais elevado é o padrão de vida, a variedade das atividades econômicas e o índice de verticalização de um local, maior é a produção de resíduos e sua composição é mais diversificada.

Um dos resíduos sólidos que sofre com esse descaso é o lodo gerado nas Estações de Tratamento de Água (ETA), caracterizado por ser um resíduo não inerte que contém 
elementos químicos nocivos ( $\mathrm{Al}, \mathrm{Fe}, \mathrm{Ti}, \mathrm{Mg}$, entre outros) à água e ao solo (RICHTER, 2001). De acordo com este autor, as disposições normalmente utilizadas são: lançamento em cursos de água, ao mar, na rede de esgotos sanitários ou em lagoas; aplicação ao solo; aterros sanitários. Por ter um custo de realização mais baixo, o descarte dos resíduos em rios é bastante empregado, entretanto, como muitas vezes os mesmos não recebem tratamento algum e são despejado sem quantidades elevadas, além de possuírem caráter poluidor para o meio ambiente.

Além da chamada consciência ecológica, outro motivo que impulsiona as empresas terem que repensar o modo como estão tratando seus resíduos é o fato de que a legislação relacionada a isso estar bem exigente, muitas vezes obrigando um descarte mais qualificado. Como exemplo, pode-se citar a Lei n. ${ }^{\circ}$ 12305/2010, a qual trata sobre a Política Nacional de Resíduos Sólidos (PNRS), trazendo ações que permitem a redução e prevenção da geração desses dejetos, além de responsabilizar os geradores, independentemente do tamanho da empresa, pelos resíduos produzidos (BRASIL, 2010).

A resolução n..$^{\circ}$ 357/2005, instituída pelo Conselho Nacional do Meio Ambiente (CONAMA), discorre em seu texto a classificação dos corpos de água e definições ambientais para o seu enquadramento, além de determinar que os efluentes de qualquer fonte poluidora poderão ser lançados nos cursos d'água somente se obedecerem os requisitos e padrões de qualidade de água presentes no próprio documento. Esta resolução sofreu complementações e modificações e um dos documentos que indica essas alterações é a Resolução n. ${ }^{\circ}$ 430/2011, o qual trata sobre as condições e padrões para descarte de efluentes em cursos d'água.

Diante deste panorama, a construção civil aparece como uma maneira interessante de aproveitar os resíduos sólidos produzidos pela ETA, pois poderia reciclar estes, auxiliando na produção de outro produto, dando um destino final eficiente ao lodo, já que seus componentes podem agregar características importantes ao novo produto, além de diminuir a emissão desses dejetos no meio ambiente e reduzir a utilização de recursos naturais na composição final, podendo também atenuar o custo final do produto.

Essas alternativas são necessárias para o ramo da construção civil, pois conforme Takaoka et. al (2013), esse setor, na escala mundial, demanda $40 \%$ de toda a energia, cerca de $33 \%$ dos recursos naturais, mesma quantidade da produção dos gases de efeito estufa, além de consumir $12 \%$ da água potável e gerar $40 \%$ dos resíduos sólidos urbanos.

Sendo assim, este trabalho visa principalmente obter a caracterização do resíduo líquido coletado durante a época das secas, na Estação de Tratamento de Água, da cidade de Várzea Grande, em Mato Grosso, analisando os parâmetros físicos e químicos do efluente, além de indicar uma possível destinação adequada para este dejeto.

Os objetivos específicos deste trabalho são:

a) Observar se a destinação desse resíduo está de acordo com os parâmetros normativos;

b) Demonstrar a importância de se fazer a análise dos parâmetros físicos, químicos e bacteriológicos do resíduo de tratamento de água para escolher a melhor decisão do que fazer com este dejeto; e

c) Indicar alternativa de destinação adequada ao lodo produzido na ETA de Várzea Grande.

\section{MATERIAL E MÉTODOS}

\section{Localização da ETA}

As amostras de resíduo proveniente da limpeza da água foram coletadas na Estação de Tratamento de Água - Departamento de Água e Esgoto (DAE) (Figura 1), situada na Avenida 
Souza T. M. M. de; Almeida A. de F.; Caracterização Físico-Química do Resíduo (Lodo) de ETA, no período de seca, em Várzea Grande MT.E\&S - Engineering and Science, (2017), 6:1.

Júlio Campos, número 2.599, Bairro Jardim dos Estados, na cidade de Várzea Grande, em Mato Grosso.

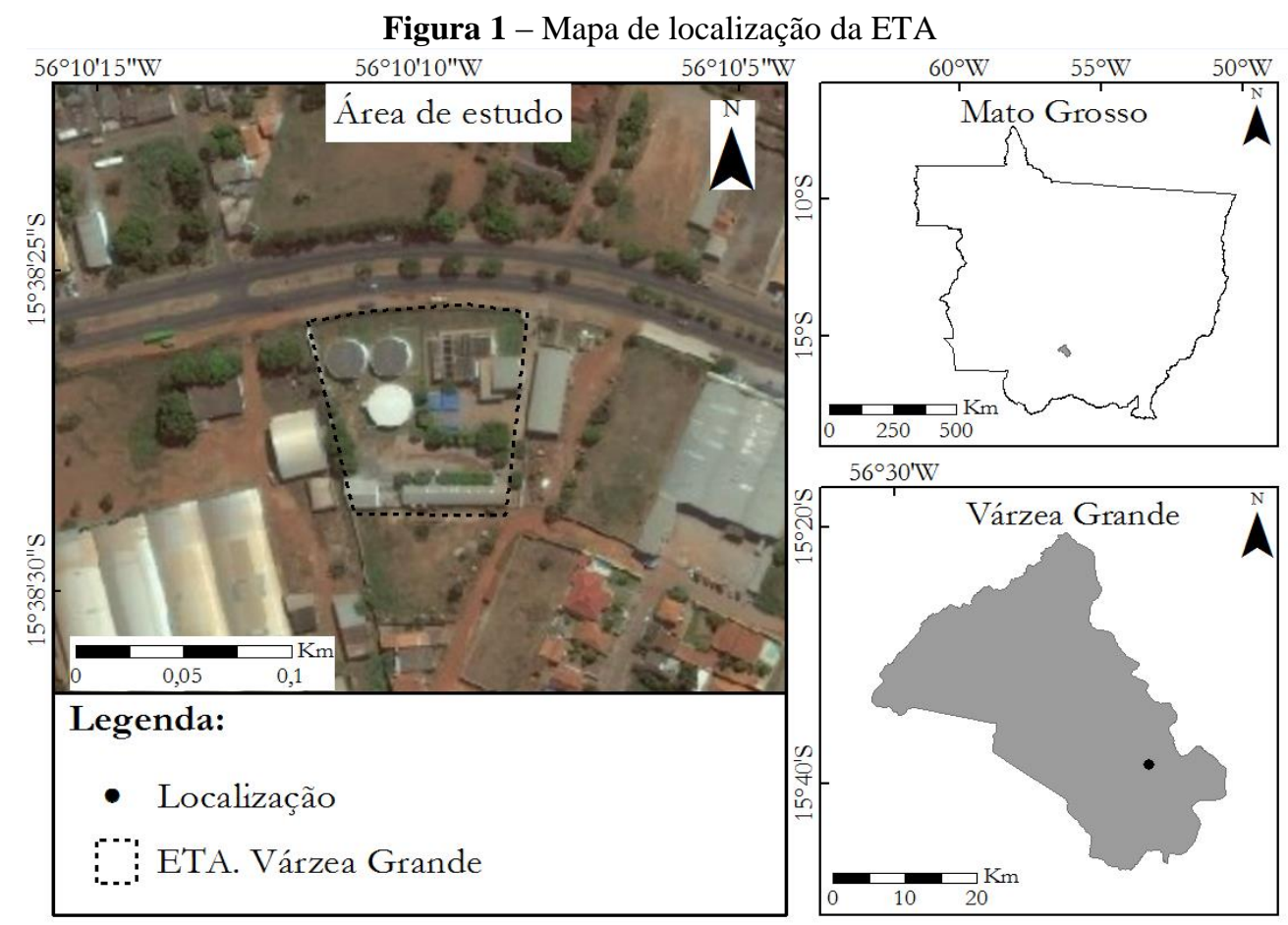

Fonte: Adaptação da imagem produzida pelo Google Maps (2015)

A ETA é responsável pelo abastecimento de água de mais de trinta bairros na cidade (informação verbal) ${ }^{1}$. O tratamento é feito no local através de duas estações instaladas (Figura 2), denominadas de ETA 1, cuja nominação se refere a construção mais antiga, feita de alvenaria, e ETA 2, representando a edificação menor construída em estrutura metálica.

Figura 2 - ETAs 1 e 2 e seus respectivos reservatórios (R1 e R2) indicados.

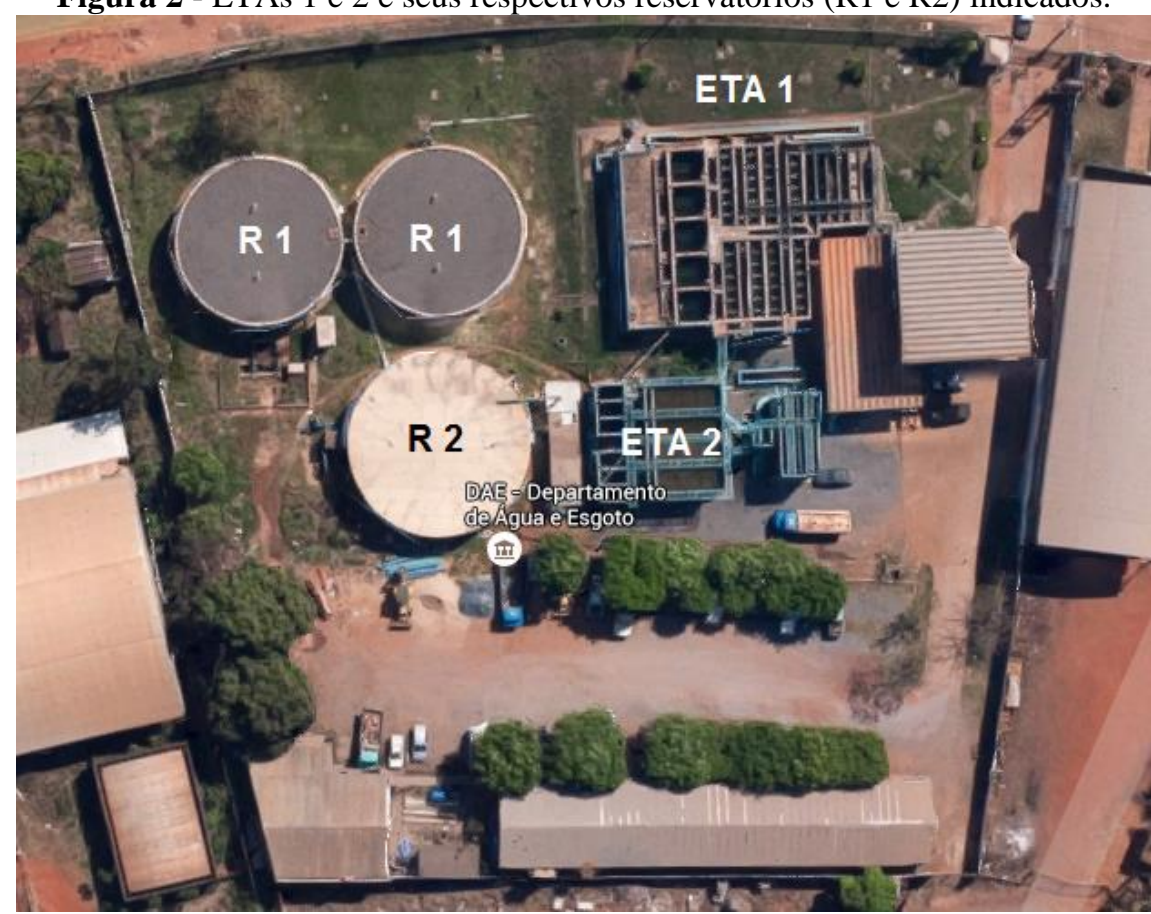

Fonte: Adaptado da imagem produzida pelo Google Maps (2015). 
De uma maneira geral, as duas estações realizam o tratamento de uma vazão de água bruta de cerca de 390 L/s, sendo 290 L/s tratados na ETA 1 e 100 L/s na ETA 2 (informação verbal) ${ }^{1}$.

Ambas as estações promovem o processo de tratamento de água convencional de ciclo completo, utilizando o sulfato de alumínio como coagulante primário, aplicado na calha Parshall presente na ETA 1 e distribuída para os tanques de coagulação das ETAs 1 e 2 . A água passa pelas etapas de mistura rápida, coagulação, floculação, decantação, filtração e desinfecção e cada uma das estações dispõem de cinco sistemas de floculação, quatro decantadores e cinco filtros.

\section{Amostragem}

Foram coletadas quatro porções de amostras, de forma mensal, em setembro e outubro de 2015, para analisar os compostos das ETAs no período seco. Em cada coleta foram armazenadas amostras líquidas do floculador, do decantador, da água de lavagem dos filtros, todas das duas ETAs, e da água bruta sem ter passado por alguma etapa de tratamento nem recebido a dosagem de sulfato de alumínio. Assim, cada porção mensal contém no total sete recipientes de amostras.

\section{Procedimentos Laboratoriais realizados}

Após a coleta dos materiais na estação (Figura 3), os mesmos foram acondicionados no refrigerador do Laboratório de Análises Físico-químicas da Universidade Federal de Mato Grosso (UFMT), Campus Cuiabá, até serem estudados.

Figura 3 - Amostras coletadas na ETA.

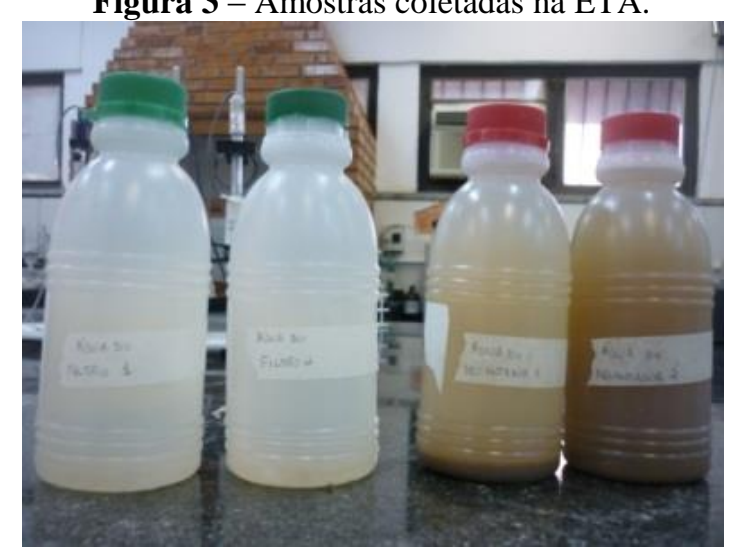

Fonte: Elaborada pelo autor.

Os processos analíticos realizados com o material coletado foram os seguintes:

a) Parâmetros físico-químicos: potencial hidrogeniônico $(\mathrm{pH})$, cor, turbidez, demanda química de oxigênio (DQO), quantidade de sólidos sedimentáveis, totais, fixos e voláteis;

b) Teor de umidade medido em base úmida;

c) Produção de sólidos estimada em cada mês analisado, por meio da seguinte equação, de acordo com AWWA (1978):

$$
\mathbf{P}=3,5 \times \mathbf{T u}^{0,66}
$$

Sendo: $\mathrm{P}$ - produção de sólidos, dado em gramas de matéria seca por metro cúbico de água bruta tratada; e Tu - turbidez da água bruta, dado em Unidade de Turbidez (UT). 
Os procedimentos de preservação, preparação e análises das amostras foram conforme as metodologias seguidas no laboratório, o qual se baseia nos seguintes métodos mostrados na Tabela 1, realizados no Laboratório de Análises Físico-Químicas da UFMT.

Tabela 1 - Parâmetros analisados nas amostras

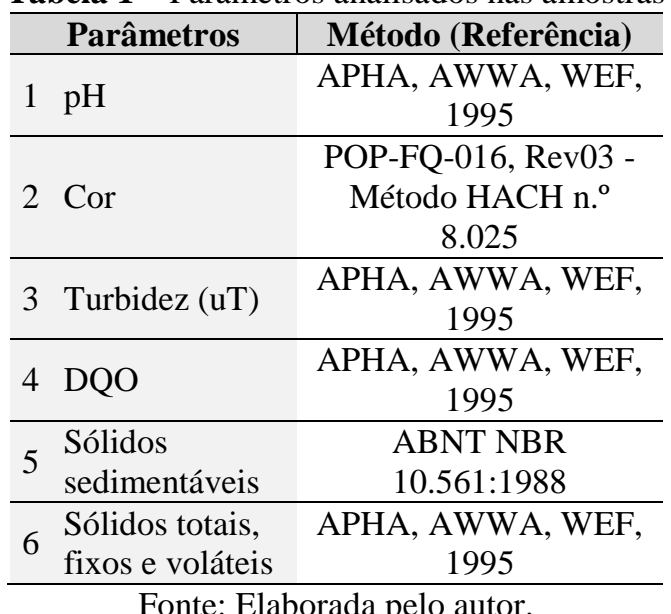

\section{RESULTADOS E DISCUSSÕES}

Os resultados estão apresentados separadamente para cada parâmetro, mostrando também valores comparativos para cada tipo de análise.

\section{Potencial hidrogeniônico}

A Tabela 2 apresenta os resultados obtidos na análise de $\mathrm{pH}$.

Tabela 2 - Análise de $\mathrm{pH}$ das amostras no período seco.

\begin{tabular}{|c|c|c|c|c|c|c|}
\hline & \multirow[b]{2}{*}{ Amostras } & \multicolumn{2}{|c|}{ Leituras - pH } & \multicolumn{3}{|c|}{ Valores comparativos } \\
\hline & & $\begin{array}{c}\text { Setembro } \\
2015\end{array}$ & $\begin{array}{c}\text { Outubro } \\
2015\end{array}$ & Montgomery (1985), & $\begin{array}{c}\text { Neubauer } \\
(1968)\end{array}$ & $\begin{array}{c}\text { Resolução } \\
\text { n. }{ }^{\circ} 430 / 2011\end{array}$ \\
\hline & Água Bruta & 7,85 & 7,83 & \multirow{7}{*}{$6-8$} & \multirow{7}{*}{$6-7,6$} & \multirow{7}{*}{$5-9$} \\
\hline \multirow{3}{*}{$\begin{array}{c}\text { ETA } \\
1\end{array}$} & Lavagem de Filtro & 7,55 & 7,07 & & & \\
\hline & Floculador & NR & 7,37 & & & \\
\hline & Decantador & NR & 7,33 & & & \\
\hline \multirow{3}{*}{$\begin{array}{c}\text { ETA } \\
2\end{array}$} & Lavagem de Filtro & NR & 7,58 & & & \\
\hline & Floculador & NR & 7,1 & & & \\
\hline & Decantador & 7,12 & 7,41 & & & \\
\hline $\mathrm{R}$ & realizado. & & & & & \\
\hline
\end{tabular}

Fonte: Elaborada pelo autor.

Observa-se que o pH apresentado possui um caráter levemente básico, variando de 7,07 a 7,85, na ETA 1 e água bruta, e de 7,1 a 7,58, encontrados na ETA 2, valores dentro do intervalo indicado por Montgomery (1985), para os lodos que utilizam o sulfato de alumínio como coagulante. Percebe-se que o resíduo da ETA 1 possui $\mathrm{pH}$ semelhante ao encontrado por Neubauer (1968), presente em estudos feitos por Rosário (2007).

Os valores de $\mathrm{pH}$ estão dentro dos limites permitido pela Resolução n. ${ }^{\circ}$ do CONAMA 430/2011 para o lançamento de efluentes poluidores diretamente no corpo de água natural, cujos valores de $\mathrm{pH}$ devem se situar entre 5 e 9. 
Souza T. M. M. de; Almeida A. de F.; Caracterização Físico-Química do Resíduo (Lodo) de ETA, no período de seca, em Várzea Grande MT.E\&S - Engineering and Science, (2017), 6:1.

Cor

A Tabela 3 mostra os teores de cor observados nas amostras da época seca, medidos em quantidade de platina-cobalto (Pt/Co) ou Unidade de Cor (UC).

Tabela 3 - Teores de cor encontrados nas amostras do período seco.

\begin{tabular}{|c|c|c|c|c|}
\hline & \multirow{2}{*}{ Amostras } & \multicolumn{2}{|c|}{ Leituras - Cor (PtCo ou uC) } & \multirow{2}{*}{$\begin{array}{c}\text { Valores comparativos } \\
\text { Scalize e Di Bernardo (2000) }\end{array}$} \\
\hline & & Setembro/2015 & Outubro/2015 & \\
\hline & Água Bruta & 77 & 76 & \multirow{7}{*}{$290-1400$} \\
\hline \multirow{3}{*}{$\begin{array}{c}\text { ETA } \\
1\end{array}$} & Lavagem de Filtro & 165 & 3690 & \\
\hline & Floculador & NR & 16840 & \\
\hline & Decantador & NR & 33000 & \\
\hline \multirow{3}{*}{$\begin{array}{c}\text { ETA } \\
2\end{array}$} & Lavagem de Filtro & NR & 1520 & \\
\hline & Floculador & NR & 2540 & \\
\hline & Decantador & 3780 & 3560 & \\
\hline
\end{tabular}

No caso dos resultados das ETAs de Várzea Grande, o teor de cor fica fora do intervalo comparativo presente na Tabela $3 \mathrm{em}$ todas as amostras coletadas nas etapas de tratamento das ETAs 1 e 2, sendo o maior valor nos decantadores, indicando uma quantidade maior de sólidos retidos neles.

\section{Turbidez e estimativa de sólidos gerados na ETA}

Os valores obtidos para a turbidez estão ilustrados na Tabela 4, medidos em unidade de turbidez nefelométrica (NTU).

Tabela 4 - Valores de turbidez das amostras coletadas no período seco.

\begin{tabular}{|c|c|c|c|c|c|}
\hline & \multirow{2}{*}{ Amostras } & \multicolumn{2}{|c|}{ Leituras - Turbidez (NTU) } & \multirow{2}{*}{\multicolumn{2}{|c|}{ Valores comparativos }} \\
\hline & & Setembro/2015 & Outubro/2015 & & \\
\hline & Água Bruta & 9,6 & 27 & & \\
\hline \multirow{3}{*}{$\begin{array}{c}\text { ETA } \\
\mathbf{1}\end{array}$} & Lavagem de Filtro & 15,5 & $445^{*}$ & $58-60$ & Scalize (1997) \\
\hline & Floculador & NR & $1060 *$ & & \\
\hline & Decantador & NR & 2080 & 3800 & Cordeiro (1993) \\
\hline \multirow{3}{*}{$\begin{array}{c}\text { ETA } \\
2\end{array}$} & Lavagem de Filtro & NR & $285^{*}$ & $58-60$ & Scalize (1997) \\
\hline & Floculador & NR & 360 & & \\
\hline & Decantador & 540 & 410 & 3800 & Cordeiro (1993) \\
\hline
\end{tabular}

Fonte: Elaborada pelo autor.

Os valores de turbidez encontrados para os decantadores se situam abaixo de $3800 \$$ NTU, valor encontrado por Cordeiro (1993) para estações que usam sulfato de alumínio como coagulante.

De posse dos valores de turbidez foi possível fazer uma estimativa da quantidade de sólidos produzida em cada etapa do tratamento de água por meio da Equação (1), cujos valores estão mostrados nas Tabelas 5 (ETA 1) e 6 (ETA 2).

Tabela 5 - Produção de sólidos estimada em cada mês analisado na ETA 1.

\begin{tabular}{c|c|c}
\hline \multirow{2}{*}{ Amostras } & \multicolumn{2}{|c}{$\begin{array}{c}\text { Quantidade de } \\
\text { sólidos }\left(\mathbf{g} / \mathbf{m}^{\mathbf{3}} \mathbf{d e}\right.\end{array}$} \\
& água tratada) \\
\cline { 2 - 3 } & Setembro & Outubro \\
& 2015 & 2015 \\
\hline
\end{tabular}


Souza T. M. M. de; Almeida A. de F.; Caracterização Físico-Química do Resíduo (Lodo) de ETA, no período de seca, em Várzea Grande MT.E\&S - Engineering and Science, (2017), 6:1.

\begin{tabular}{c|crc} 
ETA & Lavagem de Filtro & 21,364 & 195,878 \\
$\mathbf{1}$ & Floculador & NR & 347,352 \\
& Decantador & NR & 541,988 \\
\hline NR: não realizado. \\
\hline \multicolumn{3}{c}{ Fonte: Elaborada pelo autor. }
\end{tabular}

Tabela 6 - Produção de sólidos estimada em cada mês analisado na ETA 2.

\begin{tabular}{|c|c|c|c|}
\hline & \multirow[t]{2}{*}{ Amostras } & \multicolumn{2}{|c|}{$\begin{array}{l}\text { Quantidade de } \\
\text { sólidos }\left(\mathrm{g} / \mathrm{m}^{3} \mathrm{de}\right. \\
\text { água tratada) }\end{array}$} \\
\hline & & $\begin{array}{c}\text { Setembro } \\
2015\end{array}$ & $\begin{array}{c}\text { Outubro } \\
2015\end{array}$ \\
\hline \multirow{3}{*}{$\begin{array}{c}\text { ETA } \\
2\end{array}$} & Lavagem de Filtro & NR & 145,971 \\
\hline & Floculador & NR & 170,305 \\
\hline & Decantador & 222,560 & 185,569 \\
\hline \multicolumn{4}{|c|}{ NR: não realizado. } \\
\hline
\end{tabular}

\section{Demanda química de oxigênio}

A análise de DQO realizada apresentou os seguintes resultados, ilustrados na Tabela 7.

Tabela 7 - Quantidade de DQO encontrada nas amostras obtidas.

\begin{tabular}{|c|c|c|c|c|}
\hline & \multirow[b]{2}{*}{ Amostras } & \multicolumn{2}{|c|}{ Leituras - DQO* (mg/L) } & \multirow{2}{*}{$\begin{array}{c}\text { Valores comparativos } \\
\text { Singer (1974) }\end{array}$} \\
\hline & & $\begin{array}{c}\text { Setembro } \\
2015\end{array}$ & $\begin{array}{c}\text { Outubro } \\
2015\end{array}$ & \\
\hline & Água Bruta & 35 & 46 & \multirow{7}{*}{$30-5000$} \\
\hline \multirow{3}{*}{ ETA 1} & Lavagem de Filtro & NR & 95,333 & \\
\hline & Floculador & NR & 340 & \\
\hline & Decantador & NR & 1151,5 & \\
\hline \multirow{3}{*}{ ETA 2} & Lavagem de Filtro & NR & 144,333 & \\
\hline & Floculador & NR & 95 & \\
\hline & Decantador & NR & 113,5 & \\
\hline \multicolumn{5}{|c|}{ * Valores médios das leituras realizadas. } \\
\hline NR: nã & realizado. & & & \\
\hline
\end{tabular}

Fonte: Elaborada pelo autor.

Os parâmetros de DQO só puderam ser mensurados no mês de outubro, devido a problemas com os equipamentos do laboratório, sendo que o único valor de DQO obtido em setembro foi da amostra de água bruta. Analisando os dados obtidos de DQO, percebe-se que todos os resultados variam de 39 a $1151,5 \mathrm{mg} / \mathrm{L}$ e estão inseridos no intervalo definido por Singer (1974) (30 a 5000 mg/L), dado este encontrado em Rosário (2007).

\section{Sólidos sedimentáveis}

O montante de sólidos sedimentáveis observados nos exemplares coletados estão dispostos na Tabela 8 .

Tabela 8 - Teor de sólidos sedimentáveis das amostras

\begin{tabular}{|c|c|c|c|c|}
\hline & \multirow{2}{*}{ Amostras } & \multicolumn{2}{|c|}{$\begin{array}{c}\text { Leituras - Sólidos } \\
\text { sedimentáveis }(\mathrm{mL} / \mathrm{L})\end{array}$} & \multirow{2}{*}{$\begin{array}{c}\text { Valores comparativos } \\
\begin{array}{c}\text { Resolução CONAMA n. } \\
430 / 2011\end{array}\end{array}$} \\
\hline & & $\begin{array}{l}\text { Setembro } \\
2015\end{array}$ & $\begin{array}{c}\text { Outubro } \\
2015\end{array}$ & \\
\hline & Água Bruta & 0,1 & 0,1 & \multirow{4}{*}{ até 1} \\
\hline \multirow{3}{*}{ ETA 1} & Lavagem de Filtro & 15 & 53 & \\
\hline & Floculador & NR & 58 & \\
\hline & Decantador & NR & 525 & \\
\hline
\end{tabular}


Souza T. M. M. de; Almeida A. de F.; Caracterização Físico-Química do Resíduo (Lodo) de ETA, no período de seca, em Várzea Grande MT.E\&S - Engineering and Science, (2017), 6:1.

\begin{tabular}{lccc} 
& Lavagem de Filtro & NR & 32 \\
ETA 2 & Floculador & NR & 15 \\
& Decantador & 54 & 41 \\
\hline NR: não realizado. & & \\
\hline
\end{tabular}

Fonte: Elaborada pelo autor.

Segundo a Resolução n. ${ }^{\circ}$ 430/2011, os efluentes lançados em cursos d'água deve conter até $1 \mathrm{~mL} / \mathrm{L}$ de materiais sedimentáveis. Sendo assim, nota-se que a água coletada do rio possui uma quantidade aceitável de sólidos sedimentáveis. No caso dos líquidos retidos nas etapas do tratamento de água das ETAs, os resultados mostram que nenhum deles podem ser lançados diretamente nos corpos receptores sem uma diluição de sua concentração.

\section{Sólidos totais e teor de umidade}

A Tabela 9 retrata os resultados obtidos da quantidade de sólidos totais presente nas amostras das ETAs. No caso da Tabela 10, a mesma traz os resultados dos teores de umidade das amostras.

Tabela 9 - Quantidade de sólidos totais dos exemplares coletados

\begin{tabular}{|c|c|c|c|c|c|}
\hline \multirow{2}{*}{\multicolumn{2}{|c|}{ Amostras }} & \multicolumn{2}{|c|}{$\begin{array}{l}\text { Leituras - Sólidos totais* } \\
\text { (mg/L e \% da massa total) }\end{array}$} & \multicolumn{2}{|c|}{ Valores comparativos } \\
\hline & & Setembro/2015 & Outubro/2015 & Richter (2001) & Richter (2001) \\
\hline & Água & 155,667 & 126,5 & & \multirow{8}{*}{$\begin{array}{l}0,1-4 \% \text { da } \\
\text { massa total }\end{array}$} \\
\hline & Bruta & $(0,016 \%)$ & $(0,013 \%)$ & & \\
\hline \multirow{3}{*}{ ETA 1} & $\begin{array}{l}\text { Lavagem } \\
\text { de Filtro }\end{array}$ & $\begin{array}{r}614,667 \\
(0,062 \%)\end{array}$ & $\begin{array}{r}1065,5 \\
(0,107 \%)\end{array}$ & $40-1000$ & \\
\hline & Floculador & $\begin{array}{l}2180,667 \\
(0,220 \%)\end{array}$ & $3580(0,36 \%)$ & & \\
\hline & Decantador & $\begin{array}{l}5003,667 \\
(0,506 \%) \\
\end{array}$ & $\begin{array}{r}6425,5 \\
(0,641 \%) \\
\end{array}$ & $1000-40000$ & \\
\hline \multirow{3}{*}{ ETA 2} & $\begin{array}{l}\text { Lavagem } \\
\text { de Filtro }\end{array}$ & $564(0,057 \%)$ & $871(0,087 \%)$ & $40-1000$ & \\
\hline & Floculador & $\begin{array}{r}726,333 \\
(0,074 \%)\end{array}$ & $\begin{array}{r}1299,5 \\
(0,131 \%)\end{array}$ & & \\
\hline & Decantador & $\begin{array}{r}667,667 \\
(0,068 \%)\end{array}$ & $1095(0,11 \%)$ & $1000-40000$ & \\
\hline
\end{tabular}

* Valores médios das leituras realizadas.

NR: não realizado.

Fonte: Elaborada pelo autor

Tabela 10 - Umidade encontrada nas amostras

\begin{tabular}{|c|c|c|c|c|}
\hline & \multirow{2}{*}{ Amostras } & \multicolumn{2}{|c|}{ Leituras - Umidade - Base úmida* (\%) } & \multirow{2}{*}{$\begin{array}{c}\text { Valores comparativos } \\
\text { Reali (1999) }\end{array}$} \\
\hline & & Setembro/2015 & Outubro/2015 & \\
\hline & Água Bruta & \multicolumn{2}{|l|}{99,984} & \multirow{7}{*}{ no mínimo $95 \%$} \\
\hline \multirow{3}{*}{ ETA 1} & Lavagem de Filtro & 99,938 & 99,893 & \\
\hline & Floculador & 99,780 & 99,640 & \\
\hline & Decantador & 99,494 & 99,359 & \\
\hline \multirow{3}{*}{ ETA 2} & Lavagem de Filtro & 99,943 & 99,913 & \\
\hline & Floculador & 99,926 & 99,869 & \\
\hline & Decantador & 99,932 & 99,890 & \\
\hline
\end{tabular}

* Valores médios das leituras realizadas.

NR: não realizado.

Fonte: Elaborada pelo autor. 
Conforme Richter (2001), a quantidade de sólidos totais presentes no lodo de ETA varia de 0,1 a $4 \%$ da massa total. Nas amostras analisadas, nenhuma delas ultrapassa o valor de $4 \%$,estando de acordo com o que afirmou Reali (1999), o qual disse que os resíduos provenientes de ETA apresentam teor de umidade mínimo de $95 \%$. Portanto, considera-se que o lodo produzido nas ETAs 1 e 2 são de aparência líquida (RICHTER, 2001), conforme a Tabela 11.

Tabela 11 - Aparência do lodo de sulfato de alumínio

\begin{tabular}{cc}
\hline Concentração de sólidos (\%) & Aparência do resíduo \\
\hline 0 a 5 & Líquido \\
\hline 8 a 12 & Esponjoso, semissólido \\
\hline 18 a 25 & Argila ou barro suave \\
\hline \multicolumn{2}{r}{ Fonte: RICHTER (2001) }
\end{tabular}

Richter (2001) também afirma que, como a água utilizada na limpeza dos filtros possui, normalmente, um reduzido teor de sólidos $(0,004$ a $0,1 \%)$ e cerca de $5 \%$ de todos os sólidos precipitados na coagulação, o líquido pode ser remanejado para o início da cadeia de processos sem alterar consideravelmente a qualidade da água bruta. A recirculação, segundo o autor, não diminui a eficiência do tratamento e ainda pode reduzir as perdas no processo a quase zero, além de trazer certos benefícios como a redução no consumo de coagulante.

Observando os montantes encontrados de sólidos totais nas amostras de água de lavagem de filtros, nota-se que todas as leituras, excluindo a do filtro da ETA 1 no mês de outubro de 2015 por estar um pouco acima, estão dentro do esperado por Richter (2001) (entre 40 e $1000 \mathrm{mg} / \mathrm{L}$ ). No caso das leituras obtidas do líquido dos decantadores, percebe-se que apenas o resultado da ETA 2 no mês de setembro não se situou dentro do intervalo definido pelo autor acima citado (entre 1000 e $40000 \mathrm{mg} / \mathrm{L}$ ).

\section{Sólidos fixos e voláteis}

Os resultados para os parâmetros de teores de sólidos fixos e voláteis estão presentes nas Tabelas 12 e 13, respectivamente.

Tabela 12 - Teores de sólidos fixos das amostras coletadas nas ETAs

\begin{tabular}{|c|c|c|c|}
\hline \multirow{2}{*}{\multicolumn{2}{|c|}{ Amostras }} & \multicolumn{2}{|c|}{ Leituras - Sólidos fixos* (mg/L e \% de ST) } \\
\hline & & Setembro 2015 & Outubro 2015 \\
\hline & Água Bruta & NR & $114,5(90,514 \%)$ \\
\hline \multirow{3}{*}{ ETA 1} & Lavagem de Filtro & NR & $1017,5(95,495 \%)$ \\
\hline & Floculador & NR & $3422,5(95,601 \%)$ \\
\hline & Decantador & NR & $6366,5(99,082 \%)$ \\
\hline \multirow{3}{*}{ ETA 2} & Lavagem de Filtro & NR & $851,5(97,761 \%)$ \\
\hline & Floculador & NR & $1245(95,806 \%)$ \\
\hline & Decantador & NR & $1056(96,438 \%)$ \\
\hline lores & das leituras realiz & & \\
\hline
\end{tabular}

Fonte: Elaborada pelo autor.

Tabela 13 - Teores de sólidos voláteis das amostras obtidas nas ETAs

\begin{tabular}{|c|c|c|c|c|}
\hline \multirow{2}{*}{\multicolumn{2}{|c|}{ Amostras }} & \multicolumn{2}{|c|}{$\begin{array}{c}\text { Leituras - Sólidos voláteis* (mg/L e } \\
\% \text { de ST) }\end{array}$} & \multirow{2}{*}{$\begin{array}{c}\begin{array}{c}\text { Valores } \\
\text { comparativos }\end{array} \\
\text { Richter (2001) } \\
\end{array}$} \\
\hline & & Setembro 2015 & Outubro 2015 & \\
\hline & Água Bruta & NR & $12(9,486 \%)$ & \multirow{3}{*}{$8-350$} \\
\hline \multirow{2}{*}{ ETA 1} & Lavagem de Filtro & NR & $48(4,505 \%)$ & \\
\hline & Floculador & NR & $157,5(4,399 \%)$ & \\
\hline
\end{tabular}


Souza T. M. M. de; Almeida A. de F.; Caracterização Físico-Química do Resíduo (Lodo) de ETA, no período de seca, em Várzea Grande MT.E\&S - Engineering and Science, (2017), 6:1.

\begin{tabular}{cccrr} 
& Decantador & NR & $59(0,918 \%)$ & $200-14000$ \\
\hline \multirow{2}{*}{ ETA 2 } & Lavagem de Filtro & NR & $19,5(2,239 \%)$ & $8-350$ \\
& Floculador & NR & $54,5(4,194 \%)$ & \\
* Valores médios das leituras realizadas. & NR & $39(3,562 \%)$ & $200-14000$ \\
\hline
\end{tabular}

Fonte: Elaborada pelo autor.

Os teores de sólidos voláteis das amostras coletadas ficaram entre $0,918 \%$ e 9,486\%, (ou entre 90,514\% e 99,082\% no caso da porcentagem de sólidos fixos), representando valores inferiores aos encontrados pelos autores da Tabela 14.

Tabela 14 - Percentual de sólidos voláteis (SV)gerado em ETAs, segundo diversos autores.

\begin{tabular}{lc}
\multicolumn{1}{c}{ Autor (Ano) } & SV (\% de ST) \\
\hline Neubauer (1968) & 20 a 30 \\
\hline Sutherland (1969) & 25 \\
\hline Bugg (1970) & 20 \\
\hline Albrecht (1972) & 20 \\
\hline Nilsen (1974) & 30 \\
\hline Cordeiro (1981) & 20,7 \\
\hline Cordeiro (1993) & 26,3 \\
\hline Patrizze (1998) & 19 \\
\hline CETESB* (1990) ETA I & 15 \\
Piracicaba & 73 \\
\hline CETESB* (1990) ETA II & \\
Piracicaba & \\
\hline *Companhia Ambiental do Estado de São Paulo \\
OBS.: ST - Sólidos Totais \\
\hline \multicolumn{2}{c}{ Fonte: ROSÁRIO (2007) e CORDEIRO (1993). }
\end{tabular}

Observando os sólidos voláteis em valores absolutos, nota-se que todos os resultados dos lodos provenientes da lavagem de filtros se enquadram na faixa de valores indicada por Richter (2001).Em relação ao montante deste parâmetro para o resíduo dos decantadores, todos os resultados se encontram bem abaixo do intervalo encontrado por este autor.

\section{CONCLUSÕES E SUGESTÕES}

A partir dos resultados obtidos com as coletas de campo e os ensaios realizados com o lodo proveniente da ETA de Várzea Grande, pode-se afirmar que:

a) O resíduo produzido na estação não pode ser lançado diretamente nos corpos receptores, pois o nível de sólidos sedimentáveis é superior ao permitido pela Resolução n. ${ }^{\circ}$ 430/2011 em todas as etapas analisadas nas duas ETAs;

b) É possível realizar o reaproveitamento da água utilizada na lavagem dos filtros na própria estação, pois, conforme os resultados, geralmente esse líquido descartado é formado majoritariamente por água. A realização desse procedimento permite, com base na literatura pesquisada, a redução do desperdício dessa água a praticamente zero;

c) Como forma de sugestão, é necessário realizar um maior número de análises da DQO do composto da estação, pois neste estudo foi feito apenas uma vez e o conhecimento desse parâmetro é importante para indicar a concentração de matéria orgânica presente no resíduo.

\section{REFERÊNCIAS}

AMERICAN WATER WORKS ASSOCIATION, Water treatment plant sludges, Journal AWWA, 1978. 
APHA - AWWA - WEF. Standard methods for the examination of water and wastewater.19th edition. American Public Health Association, American Water Works Association and Water Enviroment Federation, 1995.

ASSOCIAÇÃO BRASILEIRA DE NORMAS TÉCNICAS. NBR 10561: Águas Determinação de resíduo sedimentável (sólidos sedimentáveis) - Método do cone de lmhoff. Rio de Janeiro, 1988.

BRASIL. Conselho Nacional Do Meio Ambiente - CONAMA. Resolução $n^{\circ}$ 357, 17 de março de 2005. Dispõe sobre a classificação dos corpos de água e diretrizes ambientais para o seu enquadramento, bem como estabelece as condições e padrões de lançamento de efluentes, e dá outras providências. Publicado no Diário Oficial da União - DOU n. ${ }^{\circ} 053$, de 18.03.2005, p. 58-63. Disponível em: <http://www.mma.gov.br/port/conama/legiabre.cfm?codlegi=459>. Acesso em: 30 de setembro de 2015.

Conselho Nacional Do Meio Ambiente - CONAMA. Resolução n. ${ }^{\circ}$ 430, 13 de maio de 2011. Dispõe sobre as condições e padrões de lançamento de efluentes, complementa e altera a Resolução n. ${ }^{\circ}$ 357, de 17 de março de 2005, do Conselho Nacional do Meio Ambiente - CONAMA. Publicado no Diário Oficial da União - DOU n. ${ }^{\circ}$ 92, de 16.05.2011, p. 89. Disponível em: <http://www.mma.gov.br/port/conama/legiabre.cfm?codlegi=646>. Acesso em: 19 de janeiro de 2016.

Política Nacional de Resíduos Sólidos, Lei 12.305. Diário Oficial da República Federativa do Brasil, Brasília, 2010. Disponível em: < http://www.planalto.gov.br/ccivil_03/_ato2007-2010/2010/lei/112305.htm>. Acesso em: 29 de setembro de 2015.

CORDEIRO, J. S. O problema dos lodos gerados em decantadores de estações de tratamento de água. São Carlos. 343p. Tese (Doutorado em Hidráulica e Saneamento) Escola de Engenharia de São Carlos, Universidade de São Paulo. 1993.

DANTAS JUNIOR, P. C. Impacto do abastecimento irregular de água nos altos índices de dengue. 67 f. Dissertação (Mestrado em Saneamento Ambiental; Meio Ambiente; Recursos Hídricos e Hidráulica) - Universidade Federal do Rio Grande do Norte, Natal, 2012.

MERCEDES, S. S. P. Perfil de geração de resíduos sólidos domiciliares no município de Belo Horizonte no ano de 1995. In: $19^{\circ}$ CONGRESSO BRASILEIRO DE ENGENHARIA SANITÁRIA E AMBIENTAL, 1997, Anais..., Foz do Iguaçu: Associação Brasileira de Engenharia Sanitária e Ambiental - ABES.

MONTGOMERY, J. M. Water Treatment Principles and Design. John Wiley\& Sons, 1985.

REALI, M. A. P. Principais características quantitativas e qualitativas do lodo de ETAs. In: REALI, M. A. P. (Coord.). Noções gerais de tratamento e disposição final de lodos de estações de tratamento de água. Rio de Janeiro: ABES. Projeto PROSAB. 1999. 
RICHTER, C. A. Tratamento de lodo de estação de tratamento de água. São Paulo: Editora Edgard BlücherLtda, 2001.

ROSÁRIO, A. C. G. Avaliação da disposição de lodo gerado numa estação de tratamento de água em reator anaeróbio de fluxo ascendente e manto de lodo (UASB). $236 \mathrm{f}$. Dissertação (Mestrado em Engenharia Hidráulica e de Saneamento) - Escola Politécnica, Universidade de São Paulo. São Paulo, 2007.

SCALIZE, P. S. Caracterização e clarificação por sedimentação da água de lavagem de filtros rápidos de estações de tratamento de água que utilizam sulfato de alumínio como coagulante primário. São Carlos: 210 p. Dissertação de mestrado - Escola de Engenharia de São Carlos - Universidade de São Paulo - USP, 1997.

SCALIZE, P. S.; DI BERNARDO, L. Caracterização da água de lavagem de filtros rápidos de estações de tratamento de água e dos sobrenadantes e sedimentos obtidos após ensaios de clarificação utilizando polímero aniônico. In: XXVII Congresso Interamericano de Engenharia Sanitária e Ambiental, 2000.

TAKAOKA, M. V. et. al. Diretrizes de ação: revisão 1. Conselho Brasileiro de Construção Sustentável (CBCS), 2013. 